\title{
DUKUNGAN KELUARGA MEMPENGARUHI KEMAMPUAN ADAPTASI (PENERAPAN MODEL ADAPTASI ROY) PADA PASIEN KANKER DI YAYASAN KANKER INDONESIA CABANG JAWA TIMUR
}

\author{
R. Khairiyatul Afiyah \\ Fakultas Keperawatan dan Kebidanan \\ Universitas Nahdlatul Ulama Surabaya \\ E-mail: eer@unusa.ac.id
}

\begin{abstract}
Most patients with Cancer cannot adapt to their disease because they assume that it is a deadly disease. The purpose of this study was to find out the correlation between family support and adaptability of patients suffered from Cancer found at Yayasan Kanker Indonesia (Indonesian Cancer Foundation) located in East Java. This analytic study using cross sectional design involved the population of all people with Cancer found at Yayasan Kanker Indonesia located in East Java, totaling 30 patients. The samples of 27 patents were collected using simple random sampling technique. The independent variable was family support, whereas the dependent variable was adaptability. Questionnaires were used to collect the data analyzed using Mann-Whitney test with the level of significance $\alpha=0.05$. The result of study showed that most of the patients $(70.4 \%)$ received good family support, whereas most of them $(63.0 \%)$ had ability to adapt to their disease. Moreover, the result of Mann-Whitney test showed that $p=0.001$ and the level of significance $\alpha=0.05$ so that $\mathrm{H}_{1}$ was accepted because $\mathrm{p}<0.05$. It showed that there was a correlation between family support and adaptability of patients suffered from Cancer found at Yayasan Kanker Indonesia located in East Java.The more family support, the more adaptive the patients with Cancer adapt to their disease. Hence, nurses are expected to give health education about the importance of family support to the family of patients with Cancer.
\end{abstract}

Keywords: Family support, Adaptability

Abstrak: Banyak pasien kanker yang tidak dapat beradaptasi dengan penyakitnya, karena berasumsi kanker adalah suatu penyakit mematikan. Tujuan penelitian ini mengetahui hubungan dukungan keluarga dengan kemampuan adaptasi pada pasien kanker di Yayasan Kanker Indonesia Cabang Jawa Timur. Desain penelitian adalah analitik dengan rancangan cross sectional. Populasi penelitian adalah seluruh pasien kanker di Yayasan Kanker Indonesia Cabang Jawa Timur sebesar 30 pasien. Sampel sebesar 27 responden dengan menggunakan teknik Simple Random Sampling. Variabel independen dukungan keluarga dan variabel dependen kemampuan adaptasi. Instrumen yang digunakan lembar kuesioner, dianalisis menggunakan uji Mann Whitney dengan tingkat signifikan $\alpha=0,05$. Hasil penelitian didapatkan sebagian besar $(70,4 \%)$ dukungan keluarga baik dan sebagian besar $(63,0 \%)$ pasien mempunyai kemampuan adaptif. Dari analisis uji Mann Whitney menunjukan hasil $p$ $=0,001$ tingkat signifikasi $\alpha=0,05$ maka H1 diterima karena $p<0,05$ berarti ada hubungan antara dukungan keluarga dengan kemampuan adaptasi pada pasien kanker di Yayasan Kanker Indonesia Cabang Jawa Timur. Semakin besar dukungan keluarga maka pasien kanker akan semakin mudah beradaptasi dengan penyakitnya. 
Saran bagi perawat adalah memberikan edukasi tentang pentingnya dukungan keluarga pada pasien kanker.

Kata Kunci : Dukungan Keluarga, Kemampuan Adaptasi.

\section{Pendahuluan}

Pada dasarnya manusia mempunyai sifat yang holistik yaitu makhluk fisik dan sekaligus psikologis yang saling mempengaruhi, sehingga apa yang terjadi dengan kondisi fisik akan mempengaruhi pula kondisi psikologis (Lubis, 2009). Kondisi tersebut dapat dialami pada seseorang dengan penyakit keganasan seperti penderita kanker. Kanker merupakan penyakit mematikan kedua setelah penyakit kardiovaskuler. Penyakit ini tidak hanya berdampak pada fisik tetapi juga psikologis. Saat pertama kali didiagnosa kanker, reaksi psikologis yang dapat muncul pada umumnya merasa shock mental, takut, tidak bisa menerima kenyataan, sampai pada keadaan depresi (Hawari, 2008). Kondisi tersebut dapat diminimalisir dengan dukungan keluarga, dukungan dapat berupa motivasi, do'a, informasi, dan emosi.

Dukungan keluarga yang baik, pasien akan merasa lebih tenang, nyaman dan akan mencapai proses adaptasi sesuai dengan teori keperawatan adaptasi dari Sister Callista Roy. Di dalam teori adaptasi Roy faktor yang terpenting untuk proses adaptasi adalah manusia, sehat-sakit, lingkungan dan keperawatan yang saling terkait. Faktor lingkungan berhubungan dengan keluarga, dalam hal ini keluarga menjadi stimulus yang dapat mengurangi tingkat kecemasan pada pasien kanker melalui dukungan yang diberikan. Saat ini banyak pasien kanker yang merasa distress emosional yang sangat berat, bingung dan sedih. Pasien akan berusaha menghindari dan melupakan hal-hal yang berhubungan dengan penyakitnya termasuk menghindari kontak sosial dan keterlibatan orangorang terdekat (anggota keluarga dan teman) dengan alasan penyakitnya adalah sesuatu yang mematikan.

Kanker merupakan penyebab kematian nomor 2 setelah penyakit kardiovaskular. Di Yayasan Kanker Indonesia cabang Jawa Timur angka kejadian kanker pada tahun 2012 sebanyak 150 kasus, pada tahun 2013 mengalami peningkatan sebanyak 165 (10\%), sedangkan pada tahun 2014 mengalami lonjakan sebanyak 215 (50\%) kasus. Jenis kanker terbanyak adalah $\mathrm{Ca}$ Serviks dengan angka kejadian tahun 2012 terdapat 51 kasus, pada tahun 2013 terdapat 60 kasus, Ca Mammae dengan angka kejadian pada tahun 2012 terdapat 32 kasus, sedangkan tahun 2013 terdapat 43 kasus, dan Ca Nasofaring dengan angka kejadian pada tahun 2012 sebanyak 15 kasus, sedangkan tahun 2013 sebanyak 21 kasus. Menurut hasil wawancara yang dilakukan kepada tiga orang penderita kanker di Yayasan Kanker Indonesia pada tanggal 08 Maret 2016. Penderita menjadi lebih sensitif kepada orang lain, merasa tidak berharga, merasa tidak kompeten lagi untuk melakukan pekerjaan apapun, dan merasa sudah tidak berharga karena penyakit ini. Dari tiga orang yang di wawancara, dua orang menyatakan mendapatkan dukungan dari anak dan suami, tetapi hanya 
sekedar menemani pasien saat menjalani pengobatan, tidak memberikan motivasi, kebutuhan sehari-hari tidak dibantu, tidak mau mendengarkan keluhan pasien. Penderita masih merasa bahwa dirinya tidak memiliki harapan untuk sembuh, tidak memiliki masa depan, dan menyerah dengan kondisi fisiknya. Namun, satu orang diantaranya menyatakan mendapatkan dukungan dari keluarga (sering memberikan motivasi, membantu kebutuhan sahari-hari, dan membantu selama proses pengobatan) membuat penderita memiliki perasaan berharga dan memiliki harapan untuk sembuh yang besar, mengingat tidak ingin meninggalkan orang yang dicintainya. Faktor-faktor yang mempengaruhi kemampuan adaptasi menurut teori adaptasi Roy dan Gunarsa, (2008) adalah manusia (perkembangan dan kematangan, keadaan psikologis), lingkungan (dukungan keluarga, rumah dan sekolah), sehat-sakit (kondisi fisik) dan keperawatan. Berdasarkan teori adaptasi Roy, individu dalam menghadapi stimulus (dampak dari penyakit kanker) akan menunjukkan respon perilaku atau mekanisme koping yang akan tergambar dalam empat bentuk modus adaptasi yaitu adaptasi fisik, konsep diri, fungsi peran, dan saling ketergantungan. Secara emosional, dukungan keluarga menjadi kebutuhan dari setiap anggotanya dan memiliki peranan penting bagi pencegahan masalah psikologis yang kerap muncul pada pasien kanker (Ozkan \& Ogze, 2008). Hal ini dikarenakan keluarga menjadi tempat untuk seseorang memperoleh kenyamanan, cinta dan dukungan emosional. Semua itu menjadi kebutuhan dari setiap anggota keluarga agar mereka menjadi bahagia, sehat, dan aman (Benokraitis,
2009). Seseorang sangat bergantung pada kemampuan adaptasi diri yang efektif untuk dapat mencapai kesembuhan. Untuk mencapai kondisi yang adaptif, teori keperawatan adaptasi Roy bisa digunakan sebagai solusi pada pasien kanker dalam memahami dan memenuhi kebutuhan adaptasi. Dukungan (motivasi, do'a, informasi, dan emosi) yang diberikan oleh anggota keluarga terhadap pasien dapat menurunkan depresi, dan meningkatkan ketenangan. Perubahan kondisi emosi menjadi tenang karena dalam rangkaian proses biokimia di dalam tubuh seseorang, hypothalamus akan merangsang kelenjar adrenal untuk menurunkan produksi hormon kortisol, yang menyebabkan detak jantung menurun, kekebalan tubuh akan meningkat, sehingga pasien mampu termotivasi untuk menjalani serangkaian proses pengobatan yang akan dijalani. Seseorang yang didiagnosa kanker membutuhkan adaptasi terhadap kondisinya. Sebagai seorang perawat mempunyai kewajiban untuk memberikan asuhan keperawatan sesuai dengan kebutuhan pasien kanker yang tidak hanya pada kondisi fisik, tetapi pada kondisi psikologis pasien juga didukung oleh teori keperawatan adaptasi Roy yang dapat diaplikasikan perawat untuk memahami proses adaptasi pasien kanker. Hal tersebut penting bagi penderita kanker karena dapat meningkatkan harapan positif terhadap kesembuhan pasien.

Tujuan penelitian ini menganalisis hubungan dukungan keluarga dengan kemampuan adaptasi (penerapan model adaptasi Roy) pada pasien kanker di Yayasan Kanker Indonesia Cabang Jawa Timur

\section{Metode Penelitian}


Jenis penelitian ini adalah analitik dengan pendekatan cross sectional yaitu untuk mengetahui hubungan dukungan keluarga dengan kemampuan adaptasi pada pasien kanker dimana kedua variabel tersebut diukur dalam satu waktu. Populasi dalam penelitian ini adalah seluruh pasien kanker di Yayasan Kanker Indonesia Cabang Jawa Timur pada bulan April yaitu sebesar 30 pasien.

Cara pengambilan sampel pada penelitian ini menggunakan pengambilan sampel secara probability sampling dengan teknik yang digunakan simple random sampling. Dimana semua subyek mempunyai kesempatan yang sama untuk dijadikan sampel dengan cara acak. Lokasi penelitian ini dilakukan di Yayasan Kanker Indonesia Cabang Jawa Timur. Waktu penelitian ini dilakukan di bulan April 2016. Variabel bebas pada penelitian ini adalah dukungan keluarga. Variabel Dependen pada peneliti ini adalah kemampuan adaptasi.

\section{Hasil dan Pembahasan}

1. Hasil Penelitian

a. Data Umum

1) Karakteristik responden berdasarkan umur.

Tabel 1 Distribusi frekuensi responden berdasarkan umur pada pasien kanker di Yayasan Kanker Indonesia Cabang Jawa Timur pada bulan April 2016.

\begin{tabular}{cccc}
\hline $\mathrm{N}$ & Usia & Frekuensi & $\begin{array}{c}\text { Persentase } \\
\mathbf{( \% )}\end{array}$ \\
\hline 1 & & & 44,4 \\
2 & 41-40 tahun & 12 & 51,9 \\
3 & $>60$ tahun & 14 & 3,7 \\
\hline & Jumlah & 1 & 100 \\
\hline
\end{tabular}

Sumber : Data Primer, April 2016

Tabel 1 menunjukkan bahwa dari 27 responden sebagian besar $(51,9 \%)$ berusia 41 - 60 tahun.

2) Karakteristik responden berdasarkan pendidikan terakhir.
Tabel 2 Distribusi frekuensi responden berdasarkan pendidikan pada pasien kanker di Yayasan Kanker Indonesia Cabang Jawa Timur pada bulan April 2016.

\begin{tabular}{cccc}
\hline $\mathrm{N}$ & Pendidikan & Frekuensi & $\begin{array}{c}\text { Persentase } \\
\mathbf{( \% )}\end{array}$ \\
\hline 1 & Dasar & 10 & 37,1 \\
2 & Menengah & 13 & 48,1 \\
3 & Tinggi & 4 & 14,8 \\
\hline & Jumlah & 27 & 100 \\
\hline
\end{tabular}

Sumber : Data Primer, April 2016.

Tabel 2 menunjukkan bahwa dari

27 responden hampir setengahnya

$(48,1 \%)$ berpendidikan menengah.

3) Karakteristik responden berdasarkan stadium kanker saat pertama kali didiagnosa.

Tabel 3 Distribusi frekuensi responden berdasarkan stadium kanker saat pertama kali didiagnosa pada pasien kanker di Yayasan Kanker Indonesia Cabang Jawa Timur pada bulan April 2016.

\begin{tabular}{|c|c|c|c|}
\hline $\begin{array}{l}\mathrm{N} \\
\mathrm{O}\end{array}$ & $\begin{array}{c}\text { Stadium } \\
\text { kanker } \\
\text { saat } \\
\text { pertama } \\
\text { kali } \\
\text { didiagnosa }\end{array}$ & Frekuensi & $\begin{array}{c}\text { Persentase } \\
(\%)\end{array}$ \\
\hline 1 & I & 6 & 22,2 \\
\hline 2 & II & 3 & 11,1 \\
\hline 3 & III & 17 & 63,0 \\
\hline \multirow[t]{2}{*}{4} & IV & 1 & 3,7 \\
\hline & Jumlah & 27 & 100 \\
\hline
\end{tabular}

Sumber : Data Primer, April 2016

Tabel 3 menunjukkan bahwa dari 27 responden sebagian besar $(63,0 \%)$ stadium kanker saat pertama kali didiagnosa yaitu stadium tiga.

4) Karakteristik responden berdasarkan tahun didiagnosa kanker.

Tabel 4 Distribusi frekuensi responden berdasarkan tahun didiagnosa kanker pada pasien kanker di Yayasan Kanker Indonesia Cabang Jawa Timur pada bulan April 2016. 


\begin{tabular}{cccc}
\hline $\begin{array}{c}\mathrm{N} \\
\mathrm{o}\end{array}$ & $\begin{array}{c}\text { Tahun } \\
\text { didiagnos } \\
\text { a kanker }\end{array}$ & $\begin{array}{c}\text { Frekuen } \\
\text { si }\end{array}$ & $\begin{array}{c}\text { Persentas } \\
\text { e }(\boldsymbol{\%})\end{array}$ \\
\hline 1 & 2011 & 4 & 14,8 \\
2 & 2012 & 1 & 3,7 \\
3 & 2013 & 2 & 7,4 \\
4 & 2014 & 10 & 37,0 \\
5 & 2015 & 9 & 33,3 \\
6 & 2016 & 1 & 3,7 \\
\hline & Jumlah & 27 & 100 \\
\hline
\end{tabular}

Sumber : Data Primer, April 2016

Tabel 4 menunjukkan bahwa dari

27 responden hampir setengahnya $(37,0 \%)$ didiagnosa kanker pada tahun 2014.

2. Data Khusus

a. Karakteristik responden berdasarkan dukungan keluarga

Tabel 5 Distribusi frekuensi responden berdasarkan dukungan keluarga pada pasien kanker di Yayasan Kanker Indonesia Cabang Jawa Timur pada bulan April 2016.

\begin{tabular}{cccc}
\hline $\begin{array}{c}\mathrm{N} \\
\mathrm{o}\end{array}$ & $\begin{array}{c}\text { Dukunga } \\
\mathrm{n} \\
\text { Keluarga }\end{array}$ & $\begin{array}{c}\text { Frekuen } \\
\text { si }\end{array}$ & $\begin{array}{c}\text { Presentas } \\
\text { e }(\%)\end{array}$ \\
\hline 1 & Baik & 19 & 70,4 \\
2 & Sedang & 3 & 11,1 \\
3 & Kurang & 5 & 18,5 \\
\hline & Jumlah & 27 & 100 \\
\hline
\end{tabular}

Sumber : Data Primer, April 2016

Tabel 5 menunjukkan bahwa dari

27 responden sebagian besar $(70,4 \%)$ mendapatkan dukungan keluarga baik.
b. Karakteristik responden

berdasarkan adaptasi psikososial

Tabel 6 Distribusi frekuensi responden berdasarkan adaptasi psikososial pada pasien kanker di Yayasan Kanker Indonesia Cabang Jawa Timur pada bulan April 2016

\begin{tabular}{cccc}
\hline No & $\begin{array}{c}\text { Adaptasi } \\
\text { Psikososial }\end{array}$ & Frekuensi & $\begin{array}{c}\text { Presentase } \\
(\%)\end{array}$ \\
\hline 1 & Adaptif & 17 & 63,0 \\
2 & Maladaptif & 10 & 37,0 \\
\hline & Jumlah & 27 & 100 \\
\hline
\end{tabular}

Sumber : Data Primer, April 2016

Tabel 6 menunjukkan bahwa dari 27 responden sebagian besar $(63,0 \%)$ adaptif.

c. Hubungan dukungan keluarga dengan kemampuan adaptasi pada pasien kanker

Tabel 7 Tabulasi silang hubungan dukungan keluarga dengan kemampuan adaptasi pada pasien kanker di Yayasan Kanker Indonesia Cabang Jawa Timur pada bulan April 2016.

\begin{tabular}{|c|c|c|c|c|c|c|c|}
\hline \multirow{3}{*}{$\begin{array}{l}\mathrm{N} \\
\mathrm{O}\end{array}$} & \multirow{3}{*}{$\begin{array}{c}\text { Dukungan } \\
\text { Keluarga }\end{array}$} & \multicolumn{6}{|c|}{ Adaptasi Psikososial } \\
\hline & & \multicolumn{2}{|c|}{ Adaptif } & \multicolumn{2}{|c|}{ Maladaptif } & \multicolumn{2}{|c|}{ Jumlah } \\
\hline & & $\mathrm{N}$ & $\%$ & $\mathrm{~N}$ & $\%$ & $\mathrm{~N}$ & $\%$ \\
\hline 1 & Baik & 17 & 89,5 & 2 & 10,5 & 19 & 100 \\
\hline 2 & Sedang & 0 & 0,0 & 3 & 100 & 3 & 100 \\
\hline 3 & Kurang & 0 & 0,0 & 5 & 100 & 5 & 100 \\
\hline & Total & 17 & 63,0 & 10 & 37,0 & 27 & 100 \\
\hline
\end{tabular}

Sumber : Data Primer, April 2016

Berdasarkan tabel 7 di atas menunjukkan bahwa dari 19 responden yang memperoleh dukungan keluarga baik hampir seluruhnya $17 \quad(89,5 \%)$ responden mampu beradaptasi atau adaptif. Dari 3 responden yang memperoleh dukungan keluarga sedang seluruhnya $3(100 \%)$ responden tidak mampu beradaptasi atau maladaptif. Dari 5 responden yang memperoleh dukungan keluarga kurang seluruhnya $5(100 \%)$ responden tidak mampu beradaptasi atau maladaptif.

Berdasarkan uji man whitney program SPSS 21 for windows didapatkan tingkat signifikasi $p=$ $0.001<a=0.005$, yang berarti Ho ditolak artinya ada hubungan dukungan keluarga dengan kemampuan adaptasi pada pasien kanker di Yayasan Kanker Indonesia Cabang Jawa Timur.

\section{Pembahasan}

\section{Dukungan keluarga}

Hasil penelitian pada tabel 5.9 diketahui bahwa sebagian besar 
$(70,4 \%) \quad$ penderita kanker mendapatkan dukungan keluarga baik. Hal ini menunjukkan bahwa tingkat kepedulian keluarga terhadap kesehatan penderita kanker diperhatikan dengan baik. Keluarga menyadari bahwa kanker dan terapinya memiliki dampak fisik dan psikologis, Jika gangguan fisik dimanifestasikan dalam bentuk keluhan nyeri, mual, sampai komplikasi organ maka gangguan psikis bisa dimanifestasikan dalam bentuk keluhan depresi, cemas, gugup, dan perasaan tidak berguna, untuk mengurangi gejala dari kanker dan pengobatannya tersebut maka keluarga memberikan dukungan agar kelangsungan pengobatan yang dijalani oleh pasien tersebut dapat berjalan dengan lancar sehingga kesehatannya meningkat dan mempunyai motivasi untuk sembuh. Tanpa dukungan keluarga, kesehatan penderita kanker akan mengalami penurunan. Karena secara psikis, kemampuan memilih, membedakan, menerima dan memutuskan apa yang baik bagi kesehatan mereka, telah mengalami penurunan juga. Menurut Gottlieb (1999) dalam Erlani (2007) mendefinisikan dukungan sosial sebagai informasi atau nasehat, bantuan nyata, atau tindakan yang diberikan oleh keakraban sosial atau berupa kehadiran dan mempunyai manfaat emosional atau berpengaruh pada perilaku penerimanya.

\section{Kemampuan Adaptasi}

Berdasarkan penelitian pada pasien kanker di Yayasan Kanker Indonesia Surabaya, tabel 5.10 menunjukkan dari 27 responden, sebagian besar (63\%) adaptif. Hal ini menunjukkan bahwa pasien kanker sudah melewati respon psikologis yang ditunjukkan dalam penelitian ini baik terkait diagnosis kanker maupun efek dari pengobatannya. Adanya diagnosis kanker dirasakan sebagai proses berduka yang sangat sulit untuk mereka hadapi. Umumnya saat pertama kali mengetahui dirinya didiagnosis penyakit kanker direspon dengan perasaan kaget dan tidak percaya (denial). Bahkan pada pasien yang harus menghadapi proses amputasi, dirasakan cukup berat dan membuat pasien tersebut mengalami proses penolakan dalam waktu yang cukup lama. Selanjutnya, pada beberapa pasien menunjukkan adanya rasa marah (anger) yang sering muncul selama proses menjalani pengobatan kanker. Keputusasaan dan sedih yang mendalam karena adanya penyakit kanker, juga dirasakan oleh pasien sebagai tahapan depresi (depression) dalam proses berduka, sehingga pada tahap ini pasien tersebut sempat untuk tidak ingin menjalani pengobatan. Akan tetapi, setelah pasien menjalani pengobatan atau terapi kanker beberapa waktu, pasien mulai merasakan ada perubahan kondisi mereka ke arah membaik, dan pada tahap ini merupakan tahap dimana pasien mulai menerima (acceptance) semua keadaan dan merasa harus tetap menjalani terapi kanker dengan harapan dapat melawan penyakit kanker tersebut. Hal ini sesuai dengan teori Elizabeth Kubbler Ross menguraikan bahwa proses berduka umumnya terjadi dalam 5 tahapan, yaitu: denial, anger, bargaining, depression atau bersedih, dan acceptance (Potter \& Perry, 2009). Hal ini juga sesuai dengan teori adaptasi Callista Roy yang memandang klien sebagai suatu system yang adaptif. Roy menguraikan bahwa bagaimana individu mampu meningkatkan kesehatannya dengan cara 
mempertahankan perilaku secara adaptif karena menurut Roy, manusia adalah mahluk holistic yang memiliki sistem adaptif yang selalu beradaptasi (Tomey \& Alligood, 2006).

Berdasarkan tabel $\quad 5.7$ menunjukkan bahwa dari 27 responden terdapat sebagian besar $(55,5 \%)$ stadium kanker responden saat ini yaitu pada stadium tiga, Pada stadium ini merupakan stadium sedang yang memungkin tumbuh harapan hidup dan motivasi untuk melawan penyakitnya sehingga responden akan memiliki rasa kepercayaan diri untuk sembuh dan menerima dengan penyakitnya. Secara tidak langsung stadium kanker berkaitan dengan fisik dan psikologis pasien kanker, hal ini sesuai dengan peryantaan McCoaughan \& Arzola (2007) dalam penelitiannya yang membuktikan bahwa pasien kanker stadium 2 dan 3 mempunyai moivasi hidup tinggi. Data ini sejalan dengan pendapat Labuorey (2007) bahwa motivasi hidup dapat meningkatkan kesehatan fisik maupun psikologis pasien kanker.

Berdasarkan tabel 5.8 menunjukkan bahwa dari 27 responden terdapat hampir setengahnya $(37,0 \%)$ didiagnosa kanker pada tahun 2014, semakin lama pengalaman dalam pengobatan pada pasien kanker maka dapat meningkatkan pemahaman dalam kehidupan sehari-hari sehingga dapat mempertahankan dan meningkatkan status kesehatannya. Hal ini sesuai dengan teori Bai et al (2009) bahwa klien yang memiliki pengalaman dengan penyakit kronis yang lebih lama dapat lebih memahami tentang hal terbaik yang harus dilakukan untuk mempertahankan status kesehatannya, yaitu salah satunya dengan menerima dengan penyakitnya.

Faktor yang dapat mempengaruhi kemampuan adaptasi yaitu salah satunya usia, seperti diketahui berdasarkan tabel 5.1 bahwa dari 27 responden sebagian besar responden $(51,9 \%)$ berusia antara 41-60 tahun. Usia 41-60 merupakan usia sudah dewasa, dimana pada usia tersebut seseorang sudah mampu berfikir matang, sudah mengerti dalam menghadapi berbagai masalah yang dihadapi dan baik buruknya suatu tindakan. Seperti pendapat Notoadmodjo (2007) umur merupakan gambaran atau tingkat kedewasaan seseorang semakin tua umur seseorang maka semakin matang cara berfikirnya sehingga berpengaruh terhadap tingkat pemahaman yang dimilikinya. Berarti dalam hal ini semakin dewasa seseorang, diharapkan mampu mengerti atau memahami apa yang seharusnya dilakukan terahadap penyakitnya.

Selain itu tingkat pendidikan juga mempengaruhi kemampuan adaptasi. Berdasarkan tabel 5.3 bahwa dari 27 responden hampir setengahnya $(48,1 \%)$ berpendidikan menengah. Tingkat pendidikan seseorang dapat mempengaruhi banyaknya pengetahuan yang dimiliki seseorang yang didapatkan melalui proses pendidikan yang dijalani baik formal maupun nonformal. Dari hasil wawancara yang dilakukan tentang pentingnya penyesuaian diri atau adaptasi dengan penyakitnya, didapatkan seluruh pasien mengetahui tentang pentingnya penyesuai diri atau adaptasi dengan penyakitnya. Menurut Mubarak (2007) pendidikan berarti bimbingan yang diberikan kepada orang lain terhadap suatu hal agar mereka dapat memahami. 
Tingkat pendidikan seseorang berpengaruh langsung terhadap pengetahuan yang dimiliki, seseorang dengan tingkat pendidikan rendah akan menghambat perkembangan sikap seseorang terhadap penerimaan informasi dan nilai-nilai yang baru diperkenalkan.

\section{Hubungan dukungan keluarga dengan kemampuan adaptasi pada pasien kanker}

Berdasarkan hasil uji statistik terhadap hubungan dukungan keluarga dengan kemampuan adaptasi pada pasien kanker melalui alat uji Mann-Whitney dengan menggunakan program SPSS versi 21.00, didapatkan nilai $p<a=0,05$, yakni 0,01. Hal ini berarti Ho ditolak atau ada hubungan dukungan keluarga dengan kemampuan adaptasi pada pasien kanker di Yayasan Kanker Indonesia Surabaya.

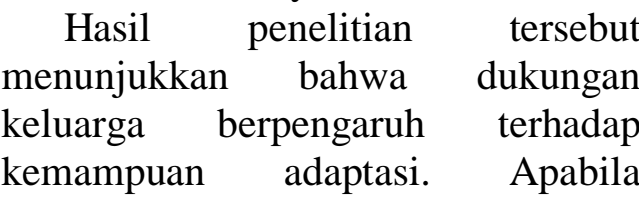
dukungan keluarga baik, maka pasien akan mudah beradaptasi dengan penyakitnya. Sebaliknya, apabila dukungan keluarga kurang, maka pasien akan sulit beradaptasi dengan penyakitnya. Bentuk bentuk dukungan yang diberikan tidak berupa saran, nasehat, atau support saja, namun berupa tindakan nyata dengan mengontrol, menjadwal, dan mendampingi ketika menjalani serangkaian pengobatan kanker. Bentuk dukungan bersifat informasional (saran, anjuran), emosional (simpati dan empati), instrumental (penyediaan makanan, pengaturan jadwal, pendampingan dan sebagainya) dan penilaian (informasi kondisi sebenarnya, penghargaan).
Dari setiap aspek dukungan keluarga memberikan kontribusi untuk membantu individu dalam menyesuaikan diri dengan penyakitnya. Dukungan informasi dan penilaian yang tinggi membuat penderita kanker merasa mampu, berharga dan dapat membantu penderita kanker dalam menjalani serangkaian pengobatan dan mengambil keputusan suatu masalah. Namun tanpa dukungan instrumental, penderita kanker merasa tidak mendapatkan bantuan yang sifatnya nyata dan langsung dalam bentuk finansial, waktu, tenaga sehingga bantuan dapat langsung menyelesaikan masalah atau mengurangi beban stress penderita kanker. Begitu juga dengan dukungan emosional yang akan membuat penderita kanker merasa tidak dicintai, dipedulikan dan diperhatikan.

Menurut Friedman (1998, dalam Setiadi 2008) keluarga dipandang sebagai suatu sistem, jika terjadi gangguan pada salah satu anggota keluarga dapat mempengaruhi seluruh sistem. Sebaliknya disfungsi keluarga dapat pula menjadi salah satu penyebab terjadinya gangguan pada anggota keluarga. Friedman juga menjelaskan keluarga merupakan sebuah sumber pertolongan praktis dan konkrit, diantaranya keteraturan menjalani terapi, Termasuk dalam hal kebutuhan makan dan minum. Jika keluarga mendukung maka penderita kanker akan termotivasi untuk sembuh karena menganggap masih ada keluarga yang peduli terhadap dirinya sehingga pasien akan mudah menerima penyakitnya.

\section{Kesimpulan}

1. Simpulan

a. Dukungan keluarga di Yayasan Kanker Indonesia Cabang Jawa 
Timur sebagian besar dukungan baik.

b. Kemampuan adaptasi di Yayasan Kanker Indonesia Cabang Jawa Timur hampir setengahnya adalah adaptif.

c. Dukungan keluarga mempengaruhi kemampuan adaptasi pada pasien kanker di Yayasan Kanker Indonesia Cabang Jawa Timur.

\section{DAFTAR PUSTAKA}

Ananta, M. D. (2015). Hubungan Antara Self-Control dengan Tingkat Agresivitas pada Remaja. Skripsi. Jakarta : Universitas Bina Nusantara.

Alligood, M R., \& Tomey, M. A. (2006). Nursing Theory Utilization \& Application. Third Edition. Mosby : St. Louis. Missouri.

Arikunto, Suharsimi (2010). Prosedur Penelitian Suatu Pendekatan Praktik. Jakarta, Rineka Cipta.

Astuti, Puji. 2012. "Analisis Praktik Residensi Keperawatan Medikal Bedah Pada Pasien Dengan Gangguan Sistem Persyarafan Dengan Penerapan Teori Adaptasi Roy Di Rumah Sakit Umum Pusat Fatmawati Jakarta". Karya Ilmiah Akhir. Spesialis Keperawatan. Universitas Indonesia.

Aziz, A. (2008). Metode Penelitian Keperawatan dan Teknik Analisa Data. Jakarta, Salemba Medika.

Clarke, N. P., Barone, H. S., Hanna, H. D., Senesac, M. P. (2011). Roy's Adaptation Model Nursing Science Quarterly.24(4). 337344.sagepub.com/journals

Permissions. Nav DOI:10.1177/08943 18411419223http://nsq.sagepub. com

Friedman, Marilya M. (2008). Keperawatan Keluarga : riset, teori \& praktik. Jakarta, Penerbit Buku Kedokteran EGC.

Gunarsa, S.D., (2008). Psikologi Perkembangan Anak dan Remaja. Jakarta: PT BPK Gunung Mulia.

Harmoko. (2012). Asuhan Keperawatan Keluarga. Penerbit: pustaka Pelajar. Yogyakarta

Hidayat, A. Aziz. Alimul (2008). Metode Penelitian Keperawatan dan Teknik Analisis Data. Jakarta, Salemba Medika.

Indah, P. S. (2015). Hubungan Dukungan Keluarga dengan Kemandirian Lannsia Dalam Pemenuhan Aktivitas Seharihari di RW 02 Desa Kelopo Sepuluh Sukodono Sidoarjo. Skripsi. Surabaya: Universitas Nahdlatul Ulama Surabaya.

Kementerian Kesehatan Republik Indonesia. Profil kesehatan Jawa Timur 2012. Jakarta: Kementerian Kesehatan Republik Indonesia

Komang (2010). Aplikasi Praktis Asuhan Keperawatan Keluarga. Jakarta, Sagung Seto.

Kusuma (2011). Metodologi Penelitian Keperawatan. Jakarta, Trans Info Media.

MRCCC Siloam Hospital, http://meetdoctor.com, diakses pada 09 Maret 2016, 19.00 WIB

Nadeak, R.J. 2010. Hubungan Dukungan Keluarga Dengan Tingkat Kecemasan Pasien Pre Operasi di Ruangan RB2 RSUP $H A M$. http://repository.usu.ac.id. di akses pada 09 Maret 2016, 22.15 WIB 
Nursalam (2008). Skripsi, Tesis, dan Intrumen Penelitian Keperawatan. Jakarta, Salemba Medika.

Potter, P. A., \& Perry, A.G. (2008). Buku ajar fundamental keperawatan: Konsep, Proses dan Praktek. Jakarta: EGC.

Ramadhaniyati. 2012. "Studi Kualitatif Tentang Adaptasi Remaja Terhadap Penyakit Kanker Yang Diderita". Tesis. Pasca Sarjana Universitas Indonesia

Retno (2007). Asuhan Keperawatan Keluarga. Jakarta, EGC.

Setiadi (2008). Konsep dan Proses Keperawatan Keluaraga. Yogyakarta, Graha Ilmu.

Sugiyono. (2011). Statistika untuk Penelitian. Bandung: Alfabeta. 